\title{
Effect of Endoscopic Ureteral Stone Treatment on Kidney Function
}

\author{
Volkan Selmi ${ }^{1}$, Sercan Sarı ${ }^{1}$, Mehmet Caniklioğlu ${ }^{1}$, Ünal Öztekin ${ }^{2}$, Mehmet Sakir Taspinar ${ }^{1}$, Levent \\ Işıkay $^{1}$
}

1. Urology, Yozgat Bozok University, Faculty of Medicine, Yozgat, TUR 2. Urology, System Hospital, Kayseri, TUR

Corresponding author: Volkan Selmi, volkanselmi@hotmail.com

\begin{abstract}
Introduction: Ureteral stones may have an influence on kidney functions due to postrenal obstruction or urinary infections. Urgent decompression or stone removal is necessary and recommended to prevent further complications in case of severe conditions such as anuria and urosepsis. Although it is believed that ureteral stone removal would result in renal function improvement, there are still unclear points on whether ureteroscopy (URS) can provide benefit as expected and has some adverse effects.
\end{abstract}

In this study, we aimed to evaluate the alteration of kidney functions of patients who undergo rigid or flexible URS for ureteral stones and find if there are any influencing factors on kidney function alteration.

Materials and Method: We analyzed 126 patients who underwent retrograde intrarenal surgery (RIRS) for renal stones between May 2018 and February 2020 prospectively. The estimated glomerular filtration rate (eGFR) was calculated on the day before the surgery, by modification of diet in renal disease (MDRD) formula. The calculation was repeated and saved three times during follow-up for the same patient; on the day after the operation, on the postoperative 30th day, and the postoperative 90th day. Then, we evaluated the renal function by comparing eGFR and assessed the predicting factors affecting the kidney function.

Results: Preoperative mean eGFR was $82.28 \pm 25.20 \mathrm{~mL} / \mathrm{min} / 1.73 \mathrm{~m}^{2}$ for the study group. Mean eGFR was calculated $90.92 \pm 22.97 \mathrm{~mL} / \mathrm{min} / 1.73 \mathrm{~m}^{2}$ on the first postoperative day, and $94.54 \pm 21.95 \mathrm{~mL} / \mathrm{min} / 1.73 \mathrm{~m}^{2}$ on the third-month follow-up. The mean change in eGFR was $8.63 \pm 16.68 \mathrm{~mL} / \mathrm{min} / 1.73 \mathrm{~m}^{2}$ in the early period and $12.26 \pm 21.09 \mathrm{~mL} / \mathrm{min} / 1.73 \mathrm{~m}^{2}$ in the long-term follow-up period. Fifty-one patients improved on chronic kidney disease (CKD) stage, and 13 deteriorated in three months follow-up.

Conclusion: Removing the stone and relieving the obstruction by ureteroscopic treatment have an alteration on eGFR. Although eGFR improves in the short-term follow-up, amelioration is evident in long-term followup, especially in female patients. The other predictive factors for eGFR improvement after URS are the presence of ureteral obstruction and high preoperative serum creatinine levels.

Review began 12/27/2020 Review ended 01/19/2021 Published 01/24/2021

\section{(๑) Copyright 2021}

Selmi et al. This is an open access article distributed under the terms of the Creative Commons Attribution License CC-BY 4.0., which permits unrestricted use, distribution, and reproduction in any medium, provided the original author and source are credited.
Categories: Urology, Nephrology

Keywords: ureteroscopy, egfr, kidney function

\section{Introduction}

Urolithiasis is one of the significant health problems with increasing prevalence due to the association with other chronic diseases such as diabetes mellitus, obesity, hypertension, metabolic syndrome, hyperlipidemia and epidemiologic factors such as changes in climate, lifestyles and diet [1]. The prevalence of ureter stones has gradually increased, reaching around $20 \%$ worldwide, and is the third most common urological problem after urinary tract infection and prostate pathologies [2]. Although stones can remain silent for a long time without any symptoms and pass spontaneously, they also can be symptomatic. Whether ureter stones remain silent for years or can show symptoms such as pain, hematuria and infection, they can damage the kidney and kidney function [3]. Renal colic caused by the obstruction of the ureteral stone is frequent and constitutes a large part of emergency department patient admission [4]. Also, it has some consequences on daily life such as workforce loss, the requirement of immediate treatment because of urosepsis and acute renal failure, and impairment of quality of life [5].

Ureteral stones were mostly treated by open surgery in the past. After the technologic developments and usage of ultrasonic and pneumatic lithotripters, minimally invasive treatment options such as shockwave lithotripsy (SWL) and percutaneous lithotripsy (PNL) took their place. Currently, by enhancement of laser fibers and flexible devices, the trend was towards endoscopic treatment especially flexible ureteroscopic management [6]. Currently, the European Association of Urology (EAU) recommends ureteroscopy (URS) or extracorporeal SWL for stone removal regarding the size and location of the ureteral stone [7]. Ureteral stones may have an influence on kidney functions due to postrenal obstruction or urinary infections. Urgent decompression or stone removal is necessary and recommended to prevent further complications in case of 
severe conditions such as anuria and urosepsis. Although it is believed that ureteral stone removal would result in renal function improvement, there are still unclear points on whether URS can provide benefit as expected and has some adverse effects.

In this study, we aimed to evaluate the alteration of kidney functions of patients who undergo rigid or flexible URS for ureteral stones and find if there are any influencing factors on kidney function alteration.

\section{Materials And Methods}

After the approval from the institutional review board (Decision Number: 2017-KAEK-189 2018.05.30 11), we analyzed 126 patients who underwent retrograde intrarenal surgery (RIRS) for ureteral stones between May 2018 and February 2020 prospectively. Patients who have prior double J catheter (DJ), solitary kidney, a history of chronic renal failure, concomitant kidney stone, ureteral stricture or urinary tract anomaly and missing data during follow-up, were excluded from the study. All patients were evaluated with non-contrast computerized tomography (CT) preoperatively and postoperatively to assess stone-free status. Patients with stones located in the ureter were investigated by complete blood count, urine analysis, urine culture and routine biochemical tests before the operation. The characteristics of the stone and the patient were recorded on the follow-up forms. The sum of the longest dimensions of stones was recorded as the stone size in the case of multiple stones. The stone density was assessed by the CT in Hounsfield Unit (HU). DJ stent was placed in patients in case of mucosal erosion, edema and hematuria. The time between starting endoscopy and end of DJ stent insertion was defined as operation time. Estimated glomerular filtration rate (eGFR) was calculated on the day before the surgery, by modification of diet in renal disease (MDRD) formula:

$\left(\mathrm{eGFR}=175 \mathrm{x}(\text { Serum creatinine })^{-1.154} \mathrm{x}(\text { age })^{-0.203} \times 0.742\right.$ [if female] $\mathrm{x} 1.212$ [if Black]).

The calculation was repeated on the postoperative first day, on the postoperative first month and the third postoperative month. All data were recorded on the follow-up form. The patients were treated with appropriate antibiotics when a urinary tract infection was diagnosed, and all interventions were performed after a sterile urine culture obtained.

Informed consent was obtained from all patients. Intravenous first-generation cephalosporin was administered 30 minutes before the surgery for surgical prophylaxis. All procedures were performed under general anaesthesia. First, the surgeon accessed the ureter by a $7.5 \mathrm{~F}$ ureteroscope (Karl Storz ${ }^{\circledR}$, Tuttlingen, Germany) under the guidance of a guidewire. The 7.5 F ureteroscope was used for diagnostic URS and ureteral dilatation in the RIRS procedure. Ureteral access sheath (Elite Flex ${ }^{\circledR}$, Ankara, Turkey) was placed in the ureter in all RIRS cases. A $7.5 \mathrm{~F}$ flexible ureteroscope (Flex-X2 ${ }^{\circledR}$, Karl Storz, Tuttlingen, Germany) was used for RIRS. A $200 \mu \mathrm{m}$ laser fiber (Ho YAG Laser; Dornier MedTech ${ }^{\circledR}$; Munich, Germany/Dornier Med-Tech $\mathrm{GmbH}$, Medilas H20 and HSolvo, Wessling, Germany) was used for laser lithotripsy. The energy of the laser was between $0.8-1.5$ Joule and $8-15 \mathrm{~Hz}$. At the end of the operation, a ureteral stent was placed in all patients. Intraoperative data were recorded, and patients who had no complications were discharged on the postoperative first day.

All patients were checked with a complete blood count, urine analysis and biochemical tests perioperatively. On the first month follow-up, in cases of no residual stone fragments requiring auxiliary interventions, the DJ catheter was displaced after the patient was examined and checked with an X-Ray. All laboratory and screening findings were recorded in the follow-up form. The patients were monitored with CT and routine laboratory tests on the third-month follow-up. The follow-up period for all patients was a minimum of three months after surgery.

All analyses were carried out using the SPSS 25.0 statistical software (IBM Corp. Released 2017. IBM SPSS Statistics for Windows, Version 25.0. Armonk, NY: IBM Corp.). The data distributions were evaluated using the Kolmogorov-Smirnov test. In case of discordance between the graphics and test results, skewness and kurtosis values were considered. Comparisons of preoperative eGFR and postoperative eGFR were performed by paired samples t-test. Other numerical data were analyzed using Student's t-test, and for categorical data, the chi-square tests were used. The possible influencing factors (age, gender, hydronephrosis, obstruction, stone location, stone volume, stone density, preoperative creatinine level) on renal function alteration, were analyzed with binominal regression analyses; $\mathrm{p}<0.05$ was considered as statistically significant.

\section{Results}

The study was conducted with 126 patients, 36 (28.6\%) women, and 90 (71.4\%) men. The mean age of the patients was $46.19 \pm 1.55$ years-old, and the mean body mass index (BMI) was $28.90 \pm 4.89$. Ten patients had comorbid diseases such as hypertension, diabetes mellitus, coronary artery disease, chronic respiratory disease, and others. Forty-nine patients had proximal ureteral stone, 31 had mid-ureteral stone while 46 had stones located in the distal ureter. Symptoms and signs of ureteral obstruction were seen in 102 patients; however, 94 of these had low grade (grades 1 and 2) hydroureteronephrosis. The mean stone volume was $316.44 \pm 277.32 \mathrm{~mm}^{3}$. The mean preoperative creatinine level was $1.00 \pm 0.33 \mathrm{mg} / \mathrm{dL}$. The 


\section{Cureus}

demographic data of the patients and stone characteristics are shown in Table 1.

\begin{tabular}{|c|c|}
\hline Parameters & $\mathrm{n}=\mathbf{1 2 6}$ \\
\hline Age (year) & $46.19 \pm 13.55$ \\
\hline \multicolumn{2}{|l|}{ Gender $(n, \%)$} \\
\hline Male & 90 (71.4\%) \\
\hline Female & $36(28.6 \%)$ \\
\hline \multicolumn{2}{|l|}{ Comorbidity (n,\%) } \\
\hline Hypertension & $1(0.8 \%)$ \\
\hline Diabetes mellitus & $1(0.8 \%)$ \\
\hline Coronary artery disease & $7(5.6 \%)$ \\
\hline Other & $1(0.8 \%)$ \\
\hline Obstruction (+/-) (n,\%) & $102(81.0 \%) / 24(19.0 \%)$ \\
\hline \multicolumn{2}{|l|}{ Hydronephrosis (n,\%) } \\
\hline No & $24(19.0 \%)$ \\
\hline Grade 1 & $41(32.5 \%)$ \\
\hline Grade 2 & $53(42.1 \%)$ \\
\hline Grade 3 & $7(5.6 \%)$ \\
\hline Grade 4 & $1(0.8 \%)$ \\
\hline \multicolumn{2}{|l|}{ Stone locallzation $(n, \%)$} \\
\hline Proximal ureter & $49(38.9 \%)$ \\
\hline Mid-ureter & $31(24.6 \%)$ \\
\hline Distal ureter & $46(36.5 \%)$ \\
\hline Number of stones & $1.11 \pm 0.42$ \\
\hline Stone volume $\left(\mathrm{mm}^{3}\right)$ & $316.44 \pm 277.32$ \\
\hline Operation time (minute) & $48.56 \pm 23.98$ \\
\hline Fluoroscopy time (second) & $12.47 \pm 22.34$ \\
\hline Hospitalization (day) & $1.67 \pm 2.32$ \\
\hline Stone-free (\%) & $93.7 \%$ \\
\hline \multicolumn{2}{|l|}{ Complication (n,\%) } \\
\hline Grade I & $9(7.1 \%)$ \\
\hline Grade II & $3(2.4 \%)$ \\
\hline Grade III & $1(0.8 \%)$ \\
\hline Grade IV & $0(0 \%)$ \\
\hline Grade V & $0(0 \%)$ \\
\hline Mean preoperative eGFR (mL/min/1.73 m²) & $82.28 \pm 25.20$ \\
\hline Mean postoperative first Day eGFR (mL/min/1.73 $\left.\mathrm{m}^{2}\right)$ & $90.92 \pm 22.97$ \\
\hline Mean postoperative third Month eGFR $\left(\mathrm{mL} / \mathrm{min} / 1.73 \mathrm{~m}^{2}\right)$ & $94.54 \pm 21.95$ \\
\hline
\end{tabular}

TABLE 1: Characteristics of Patients and Stones and Operation Outcomes 


\section{Cureus}

BMI: body mass index, eGFR: estimated glomerular filtration rate.

Ninety-three patients (73.8\%) underwent semirigid URS while flexible URS was performed in 33 (26.2\%). DJ catheter was placed in all patients except two. The mean operative time was $48.56 \pm 23.98$ minutes. The stone-free rate of the study was $93.7 \%(\mathrm{n}=118)$. Totally, 13 (10.3\%) patients had surgical complications that were mostly low-grade such as fever, hematuria and urinary tract infection. Only one patient required surgical intervention because of steinstrasse. The operation outcomes are also shown in Table 1.

Preoperative mean eGFR was $82.28 \pm 25.20 \mathrm{~mL} / \mathrm{min} / 1.73 \mathrm{~m}^{2}$ for the study group. Mean eGFR was calculated $90.92 \pm 22.97 \mathrm{~mL} / \mathrm{min} / 1.73 \mathrm{~m}^{2}$ on the first postoperative day, and $94.54 \pm 21.95 \mathrm{~mL} / \mathrm{min} / 1.73 \mathrm{~m}^{2}$ on the third-month follow-up. The mean change in eGFR was $8.63 \pm 16.68 \mathrm{~mL} / \mathrm{min} / 1.73 \mathrm{~m}^{2}$ in the early period and $12.26 \pm 21.09 \mathrm{~mL} / \mathrm{min} / 1.73 \mathrm{~m}^{2}$ in the long-term follow-up period. There was a statistically significant improvement in eGFR in the short-term and long-term follow-up when compared to preoperative renal function $(\mathrm{p}<0.05)$. Thirty-six patients had improvement, and eight patients had a deterioration of their chronic kidney disease (CKD) stage in the early follow-up period. Fifty-one patients improved on CKD stage, and thirteen deteriorated in three months follow-up. The comparison of eGFR alteration and renal functional outcomes preoperative and postoperative periods are shown in Tables 2 and 3.

\begin{tabular}{|c|c|c|c|c|}
\hline \multirow{4}{*}{ Mean eGFR $\left(\mathrm{mL} / \mathrm{min} / 1.73 \mathrm{~m}^{2}\right)$} & \multicolumn{2}{|c|}{ Follow-up period } & \multirow[t]{2}{*}{ eGFR change } & \multirow[t]{2}{*}{ p-Value } \\
\hline & Preoperative & Postoperative first day & & \\
\hline & $82.28 \pm 25.20$ & $90.92 \pm 22.97$ & $8.63 \pm 16.68$ & $<0.05$ \\
\hline & Preoperative & \multicolumn{3}{|c|}{ Postoperative third month } \\
\hline & $82.28 \pm 25.20$ & $94.54 \pm 21.95$ & $12.26 \pm 21.09$ & $<0.05$ \\
\hline
\end{tabular}

\section{TABLE 2: Comparison of eGFR Alteration During Follow-Up}

eGFR: estimated glomerular filtration rate; Statistical significance in italic.

\begin{tabular}{|c|c|c|}
\hline & Preoperative $(n=126)$ & Postoperative third month \\
\hline \multicolumn{3}{|l|}{ CKD group $(n, \%)$} \\
\hline Stage I & $50(39.7 \%)$ & 76 (60.3\%) \\
\hline Stage II & $52(41.3 \%)$ & 42 (33.3\%) \\
\hline Stage III & $21(16.7 \%)$ & $8(6.3 \%)$ \\
\hline Stage IV & $3(2.4 \%)$ & $0(0 \%)$ \\
\hline Stage V & $0(0 \%)$ & $0(0 \%)$ \\
\hline CKD stage improvement $(\mathrm{n}, \%)$ & & $51(40.5 \%)$ \\
\hline CKD stage deterioration (n,\%) & & $13(10.3 \%)$ \\
\hline
\end{tabular}

\section{TABLE 3: Renal Function Analysis}

CKD: chronic kidney disease.

In the multinominal regression analysis, preoperative creatinine level, gender and presence of ureteral obstruction had significant effects on kidney function improvement. In the analysis, it was observed that; as the preoperative creatinine level increased, the kidney function improvement became more evident, so there was a positive correlation between preoperative creatinine level and recovery $(B=10.43 ; p=0.000004)$. The analysis result was that the improvement in females was more evident than in males $(B=1.84 ; p=0.034)$. In the presence of ureteral obstruction, it is seen that the improvement was more significant than the absence 
of obstruction. The presence of ureteral obstruction positively correlates with recovery $(B=1.73 ; p=0.03)$.

\section{Discussion}

The size and location of the stone are the most influencing parameters while deciding for the treatment for ureteral stones [8]. Urologists evaluate the patients and perform a surgical intervention according to these factors. Current guidelines recommend URS over SWL for ureteral stones greater than $10 \mathrm{~mm}$ and both for ureteral stones smaller than $10 \mathrm{~mm}$ [7]. Although semirigid URS can be used for stone removal in the whole ureter, flexible URS is more successful than semirigid URS for stones located in the proximal ureter $[9,10]$. In this study, we performed flexible URS in 33 of 49 patients who had a proximal ureteral stone. The stones located in the distal and mid-ureter were removed with semirigid URS.

Kirac compared conventional medical treatment, tamsulosin $0.4 \mathrm{mg}$ daily in addition with conventional medical treatment and semirigid URS for distal ureteral stones, and reported that ureteroscopic intervention had higher stone-free rates (95.6\%) when compared to others (48.7\% and 58.5\%, respectively, p<0.0001) [11]. Tugcu et al. achieved a $96.7 \%$ stone-free rate for distal ureteral stones treated primarily with semirigid URS and a 95.6\% stone-free rate for distal ureteral stones that failed SWL treatment and then underwent semirigid URS [12]. Kartal et al. compared treatment options for proximal ureteral stones and reported stone-free rates as $67.2 \%$ on the 15 th postoperative day and $94.1 \%$ on the third postoperative month after semirigid URS. In the same study, stone-free rates for flexible URS were $89.6 \%$ and $97 \%$, respectively [13]. Data in the literature demonstrate that urologists can achieve a high success rate for ureteral stones with semirigid URS. In this study, the stone-free rate was $93.7 \%$ which was consistent with previous studies in the literature.

The surgical complication rate of URS has been reported in a wide range. Most of these complications were lower grade and can be managed with conservative treatment [14]. Tepeler et al. evaluated 1208 patients who underwent URS for ureteral stone and reported that the overall complication rate was $12.6 \%$ [15]. The most common complications were proximal stone migration (3.9\%), mucosal injury (2.8\%) and bleeding (1.9\%). Urinary tract infection (8\%) and stone migration (8\%) were the most common complications. In our study, the surgical complication rate (10.3\%) was similar to the previous studies.

There are limited studies that reported renal function alteration of ureteral stones and ureteroscopic lithotripsy while several studies evaluated the impact of urolithiasis and its treatment on kidney function [16-19]. Ureteral stones can cause changes in GFR depending on the level of ureteral obstruction they cause. Complete ureteral obstruction decreases eGFR, while partial obstruction has variable effects depending on the severity and duration of the obstruction [20]. In the literature, it is stated that relief of the post-renal obstruction improved renal function. In an animal model, GFR was decreased to $<10 \%$ of baseline after unilateral ureteral obstruction and returned to the baseline level by 14 days after obstruction relief [21]. In another similarly designed study, GFR was decreased in three hours after the relief of ureteral obstruction but returned to normal level in two weeks period [22]. In this study, both short- and long-term kidney function was improved statistically significantly after ureteroscopic lithotripsy. eGFR change was more in the late period than the early period. Outcomes of this study were consistent with the previous literature findings on ureteral obstruction treatment and kidney function.

Reeves et al. evaluated the effect of ureteroscopic lithotripsy on kidney functions in patients with CKD and reported that the majority of the patients remained stable or improved in their CKD status [19]. Hoarau et al. retrospectively analyzed patients who underwent retrograde intrarenal surgery and stated that $4.9 \%$ of patients had significant renal function deterioration while $14.1 \%$ had significant renal function improvement [23]. In this study, $40.4 \%$ of patients improved CKD status while $10.3 \%$ deteriorated, and $49.3 \%$ remained stable. These findings were consistent with the data in the literature.

In multinominal logistic regression analysis, gender, preoperative creatinine level and presence of obstruction were significant predictive factors for renal function improvement after ureteroscopic treatment of ureteral stones. Female gender was a predictive factor in our study as same as Piao's, which explained this was a result of the inhibitor roles of female hormones during inflammatory processes [24]. Higher preoperative serum creatinine level was associated with improvement in renal function after URS. Although Hoarau et al. mentioned multiple procedures and pre-existing CKD were two crucial factors for renal deterioration in univariate analysis, they reported that these factors were not predictive in multivariate analysis. However, they evaluated renal function for the treatment of stones that were located in the kidney, and $63.8 \%$ of patients had preoperative ureteral stents. This difference could be explained by the disparity of patient characteristics, and also acute renal insufficiency may be much more predictive than chronic conditions. The other predictive factor was the presence of ureteral obstruction, which may impair the urine flow and cause renal insufficiency. Thus, relief of the obstruction may have a positive impact on renal function [25].

This study has potential limitations. The research was conducted in a single center with a small number of patients. Also, eGFR was the main factor while assessing renal function. Therefore, multicenter prospective randomized controlled trials designed with more specific laboratory, molecular and imaging tests will have a contribution to the literature. 


\section{Conclusions}

Endoscopic treatment of ureteral stones is the most effective treatment with a low complication rate. Ureteral obstruction, which was the result of an impacted ureteral stone, deteriorates kidney function. Removing the stone and relieving the obstruction by ureteroscopic treatment have an alteration on eGFR. Although eGFR improves in the short-term follow-up, amelioration is evident in long-term follow-up, especially in female patients. The presence of ureteral obstruction and high preoperative serum creatinine levels are the other predictive factors for improvement after URS. However, further prospective randomized controlled studies conducted with a large number of patients and more specific tests such as cystatin C and radionucleotide scans may confirm the outcomes of this study.

\section{Additional Information \\ Disclosures}

Human subjects: Consent was obtained or waived by all participants in this study. Yozgat Bozok University Clinical Trials Ethics Committee issued approval 2017-KAEK-189_2018.05.30_11. Animal subjects: All authors have confirmed that this study did not involve animal subjects or tissue. Conflicts of interest: In compliance with the ICMJE uniform disclosure form, all authors declare the following: Payment/services info: All authors have declared that no financial support was received from any organization for the submitted work. Financial relationships: All authors have declared that they have no financial relationships at present or within the previous three years with any organizations that might have an interest in the submitted work. Other relationships: All authors have declared that there are no other relationships or activities that could appear to have influenced the submitted work.

\section{References}

1. Khan A: Prevalence, pathophysiological mechanisms and factors affecting urolithiasis . Int Urol Nephrol. 2018, 50:799-806. 10.1007/s11255-018-1849-2

2. Saeed S, Ullah A, Ahmad J, Hamid S: The prevalence of incidentally detected urolithiasis in subjects undergoing computerized tomography. Cureus. 2020, 12:e10374. 10.7759/cureus.10374

3. Marchini GS, Vicentini FC, Monga M, et al.: Irreversible renal function impairment due to silent ureteral stones. Urology. 2016, 93:33-39. 10.1016/j.urology.2016.02.042

4. Sfoungaristos S, Kavouras A, Perimenis P: Predictors for spontaneous stone passage in patients with renal colic secondary to ureteral calculi. Int Urol Nephrol. 2012, 44:71-79. 10.1007/s11255-011-9971-4

5. Rabah DM, Alomar M, Binsaleh S, Arafa MA: Health related quality of life in ureteral stone patients: postureterolithiasis. Urol Res. 2011, 39:385-388. 10.1007/s00240-011-0375-9

6. Selmi V, Sari S, Cakici MC, Ozdemir H, Kartal IG, Ozok HU, Imamoglu MA: Does previous failed shockwave lithotripsy treatment have an influence on retrograde intrarenal surgery outcome?. J Laparoendosc Adv Surg Tech A. 2019, 29:627-630. 10.1089/lap.2018.0487

7. EAU Guidelines on Urolithiasis. (2020). Accessed: January 23, 2020: https://uroweb.org/guideline/urolithiasis/.

8. Wright AE, Rukin NJ, Somani BK: Ureteroscopy and stones: current status and future expectations. World J Nephrol. 2014, 3:243-248. 10.5527/wjn.v3.i4.243

9. Galal EM, Anwar AZ, El-Bab TK, Abdelhamid AM: Retrospective comparative study of rigid and flexible ureteroscopy for treatment of proximal ureteral stones. Int Braz J Urol. 2016, 42:967-972. 10.1590/S16775538.IBJU.2015.0644

10. Preminger GM, Tiselius HG, Assimos DG, et al.: 2007 guideline for the management of ureteral calculi . J Urol. 2007, 178:2418-2434. 10.1016/j.juro.2007.09.107

11. Kirac M, Atkin MS, Deniz N, Biri H: Ureteroscopy: the first line treatment for distal located ureteral stones smaller than $10 \mathrm{~mm}$. Urol J. 2014, 11:1915. 10.22037/uj.v10i4.1556

12. Tugcu V, Gurbuz G, Aras B, Gurkan L, Otunctemur A, Tasci AI: Primary ureteroscopy for distal-ureteral stones compared with ureteroscopy after failed extracorporeal lithotripsy. J Endourol. 2006, 20:1025-1029. 10.1089/end.2006.20.1025

13. Kartal I, Baylan B, Cakici MC, Sari S, Selmi V, Ozdemir H, Yalcinkaya F: Comparison of semirigid ureteroscopy, flexible ureteroscopy, and shock wave lithotripsy for initial treatment of 11-20 mm proximal ureteral stones. Arch Ital Urol Androl. 2020, 92:39-44. 10.4081/aiua.2020.1.39

14. Whitehurst LA, Somani BK: Semi-rigid ureteroscopy: indications, tips, and tricks. Urolithiasis. 2018, 46:3945. 10.1007/s00240-017-1025-7

15. Tepeler A, Resorlu B, Sahin T, et al.: Categorization of intraoperative ureteroscopy complications using modified Satava classification system. World J Urol. 2014, 32:131-136. 10.1007/s00345-013-1054-y

16. Lee C, Ugarte R, Best S, Monga M: Impact of renal function on efficacy of extracorporeal shockwave lithotripsy. J Endourol. 2007, 21:490-493. 10.1089/end.2006.0319

17. Shi X, Peng Y, Li L, et al.: Renal function changes after percutaneous nephrolithotomy in patients with renal calculi with a solitary kidney compared to bilateral kidneys. BJU Int. 2018, 122:633-638. 10.1111/bju.14413

18. Zhou Y, Gurioli A, Luo J, Li Z, Zhu J, Li J, Liu Y: Comparison of effect of minimally invasive percutaneous nephrolithotomy on split renal function: single tract vs multiple tracts. J Endourol. 2017, 31:361-365. 10.1089/end.2016.0822

19. Reeves T, Pietropaolo A, Somani BK: Ureteroscopy and laser stone fragmentation is safe and tends to improve renal function in patients with chronic kidney disease: prospective outcomes with a minimum follow-up of 6 months. J Endourol. 2020, 34:423-428. 10.1089/end.2019.0784

20. Partin AW, Peters CA, Kavoussi LR, Dmochovski RR, Wein AJ: Campbell Walsh Wein Urology, 12th Edition . Elsevier, Philadelphia; 2020. https://www.mea.elsevierhealth.com/campbell-walsh-wein-urology- 


\section{Cureus}

9780323546423.html.

21. Ito K, Chen J, El Chaar M, et al.: Renal damage progresses despite improvement of renal function after relief of unilateral ureteral obstruction in adult rats. Am J Physiol Renal Physiol. 2004, 287:1283-1293.

10.1152/ajprenal.00441.2003

22. Bander SJ, Buerkert JE, Martin D, Klahr S: Long-term effects of 24-hr unilateral ureteral obstruction on renal function in the rat. Kidney Int. 1985, 28:614-620. 10.1038/ki.1985.173

23. Hoarau N, Martin F, Lebdai S, Chautard D, Culty T, Azzouzi AR, Bigot P: Impact of retrograde flexible ureteroscopy and intracorporeal lithotripsy on kidney functional outcomes. Int Braz J Urol. 2015, 41:920926. 10.1590/S1677-5538.IBJU.2014.0402

24. Piao S, Park J, Son H, Jeong H, Cho SY: Evaluation of renal function in patients with a main renal stone larger than $1 \mathrm{~cm}$ and perioperative renal functional change in minimally invasive renal stone surgery: a prospective, observational study. World J Urol. 2016, 34:725-732. 10.1007/s00345-015-1653-x

25. Nishi M, Matsumoto K, Fujita T, Iwamura M: Improvement in renal function and symptoms of patients treated with laparoscopic pyeloplasty for ureteropelvic junction obstruction with less than $20 \%$ split renal function. J Endourol. 2016, 30:1214-1218. 10.1089/end.2016.0553 